\title{
Various Perspectives on Performance Appraisals in the Health Service
}

\author{
Frøydis Vasset \\ Social Science, Aalesund University College, Aalesund, Norway \\ Email: fv@hials.no
}

Received 27 February 2014; revised 29 March 2014; accepted 6 April 2014

Copyright (C) 2014 by author and Scientific Research Publishing Inc.

This work is licensed under the Creative Commons Attribution International License (CC BY). http://creativecommons.org/licenses/by/4.0/

(c) (7) Open Access

\begin{abstract}
Background: The health services are facing many new challenges, including a growing number of elderly patients, and an increasing use of technology in the work place. These challenges might require flexible and reflective conversations with the employees. Aim: This study examines whether some performance appraisals (PAs) are more efficient and more effective than others. The study also shows how some performance appraisals are more suitable for home care and nursing homes in municipal health services. Methods: Two datasets are used: 1) a questionnaire was distributed to a representative sample of 600 health personnel in Norway; and 2) a questionnaire was distributed to a representative sample of 60 employees (test-group: 10 groups; control-group: 30 employees), in pre-test, post-test 1 and post-test 2. SPSS. Findings: Managers are the only ones who receive training in PA techniques (factory perspective). Nurses versus auxiliary nurses experience more frequent dyadic relationships and exchanges in PAs (family perspective). PAs for employees from nursing homes are fairer than those administered to home care employees (jungle perspective). In organizations closest to carnival perspectives, employees participating in group-PAs are more active in the conversations than employees who have individual conversations in PAs. Conclusions: Health personnel involved in PAs experience different effects of the conversational, and employees working as a member of a team in the organization need to experience a high quality of relationships (family), justice (jungle), and participation in groupconversation (carnival) during performance appraisals.
\end{abstract}

\section{Keywords}

Performance Appraisal, Health Services

\section{Introduction}

Performance appraisals (PAs) are described as a search for better, more accurate, and more cost effective communication techniques for measuring job performance and job satisfaction. PAs are considered as an important 
technique for improving an organization's performance [1]-[5].

PAs can be perceived, described and implemented in different ways in organizations. Various PA techniques are used, and managers/organizations can have different perspectives on how the conversation will best be conducted and utilized. This may again lead to different effects from the conversation.

This study aims to investigate whether some PA perspectives in municipal health services can be seen as more efficient and more effective than others.

When measured in man-labour years, the municipal health services in Norway are larger than the hospital sectors. Both these sectors are growing rapidly due to an increasingly older population. Neither Norwegian nor international research provides a thorough picture of the relationships between life expectancy, disabilities and need for nursing services [6]. However, the municipal health services have fewer managers and many employees compared to other occupations (1 per 70 - 80), and their services are provided around the clock during, every week of the year. These services, mostly in nursing homes and home care, are also characterized by work complexity, high levels of sick leave among the staff, and the infusion of new technology [7]. Most of the employees in these services are trained nurses and auxiliary nurses [3] [7]-[9].

\section{Bolman and Deal's Organizational Model}

Bolman and Deal's (2009) organizational model of four organizational perspectives will be used to highlight several points of view and opinions in PAs. This model is ideal for examining PAs because organizations can reflect on the various models and ascertain whether the conversations are useful to them. These perspectives describe organizations through factory, family, jungle and carnival metaphors [10].

\subsection{Performance Appraisals Illustrated through a "Factory" Perspective}

The factory perspective (Table 1) indicates a top-down organizational structure which has a long tradition in implementing PAs. These organizations use the same procedure year after year, and the managers have all of the power in personnel policies. They focus on the organization's goals, and have one manager who is responsible for the PAs. The factory perspective has rigid rules for implementation, and strict procedures and systems for administering PAs. This tradition believes that managers should receive most of the training in PA interviewing [7] because managers have the primary responsibility for the conversations. These organizations have annual PAs often during the same season, and use the manager's office (manager's territory) for implementations. Historically, information from PAs has been used as a basis for administrative decisions [2] [10]. Several service institutions are using a PA system that was developed at a time when organizations were typically large and hierarchically arranged, (as organizational environments were relatively stable) when employees were homogeneous and relatively well qualified, and when long-term employment was the norm [2]. Given the manager centeredness of the factory milieu some employees try to reduce their anxieties by minimizing the importance of PAs, e.g. making them sound as if they are trivial or unnecessary [11].

Research suggests that organizations undermine the PA process by giving it too little attention, by minimizing employee participation in PAs, and by failing to provide enough training and clear lines of accountability [11][15]. Based upon previous research, I thus propose the following hypothesis:

Hypothesis 1.

Health services, mainly organized according to the "factory" perspective only facilitates manager training in performance appraisals.

Table 1. A four-by-four table describing Bolman and Deal's theory.

\begin{tabular}{cccc}
\hline Factory & Family & Jungle & Carnival \\
Structured & Human resources & Political & Symbolic \\
Excellence & Exchanges & Power/justice & Culture \\
Authorship & Human relationships & Conflicts & Inspiration/learning \\
Technology & Needs/caring & Distribution & Create/faith \\
\hline
\end{tabular}




\subsection{Performance Appraisals Illustrated through a "Family" Perspective}

Bolman and Deal's (2009) model also takes the family unit (Table 1) as a metaphor for the organization. Research points out that "employees and managers must arrange to be relaxed, and have informal seating. Avoid sitting behind a desk, as this may be a physical barrier between manager and the subordinates. The other's comments must be received without interruption" (16:30). Moreover, it is vital to "repeat what has been said as objectively as possible. This is a core means of building empathy, and shows what has been said and what has been understood" (16:35).

PA must be "tailored" to each employee. For employees, the PA's objectives may be to maximize their employment benefits in the form of well-being, learning and career development. PAs may be practical tools for realizing these benefits and for creating work conditions that enable employees to do the job. The PA conversation will also ensure that the organization will benefit greatly from the employment. In short, the employees and the organization are given opportunity to exchange important information in a family-like setting, and the employees themselves are given opportunity to develop their professional skills [10] [15].

Research argues that a well-prepared PA allows both managers and employees to have prior knowledge about the conversation's topics. Jointly working through the points in the PA guide increases the likelihood that all participants will learn something new [15].

A systematic PA indicates that there are some particularly important points for the organization and for the employees [15]. At the same time, some managers have little confidence in their ability to handle PAs effectively, and consequently, they tend to cling to the paperwork instead of holding useful PAs. Other managers may have an exaggerated idea of what PAs involve and what the conversations require of them as managers [15].

Research suggests that training in the use of PAs should be implemented as close as possible to the time of the first conversation. Many courses include videotapes or training films, either produced in-house or obtained from external sources [11]. High-quality exchanges and human relationships in the workplace may lead to high quality relationships in the PA [9]. Nurses, unlike auxiliary nurses, often share the same educational level as their managers, and thus have additional opportunities to further their competence during PAs. They are better at pointing out errors in PAs, providing messages, and discussing relevant topics and problems [7]. The following hypothesis reflects on dyadic relationships and exchanges in PAs.

Hypothesis 2.

In health services mainly organized by "family" perspectives,

1) active participation in the performance appraisal will be higher for nurses than auxiliary nurses.

2) the quality of relationships and exchanges in the performance appraisal will be higher for nurses than for auxiliary nurses.

\subsection{Performance Appraisals Illustrated through the Use of a "Jungle" Perspective}

Bolman and Deal's (2009) third perspective is the jungle concept [10] (Table 1). Competition between important tasks may resemble a jungle especially when resources are limited, as in the case of Norwegian municipalities. PAs may be given lower priority or given little emphasis [6]. Where the jungle prevails, PAs might be mistreated as an interview, an interrogation or an arena for venting accumulated frustrations. Instead they should be a time for giving credit [15]. The municipal health services in Norway have departments with approximately 40 - 80 subordinates [6] [7] [9], but the large health institutions from 1950-60 have nearly vanished. Approximately $80 \%$ of the municipal health services in Norway are reserved for home care, but the new flat organizational structure in municipalities increases the number of subordinates per manager [6] [10].

Several researchers suggest that there is "no best way" to conduct PAs, although the technique depends in part on the situation and the quality of dyadic exchanges and relationships in the sector [2] [5]. In particular, it is argued that most people are inherently poor at receiving criticism, and even if critical feedback forms only a small part of the PA, it is likely viewed by the recipient as representative of the entire interview [16]. This reaction to criticism might be even more heightened in the jungle setting.

PAs might be especially challenging in the home-care arena. When compared with employees in institutional setting, home-care employees must take a greater degree of responsibility for their work, and the manager does not have the ability to continuously monitor nurse's in their daily work [17]. This may lead to additional conflicts, misunderstandings and injustices. These unique characteristics where employees work alone and unsupervised in patient's homes [18] must be included in PAs as traditional models may be inappropriate for clinicians 
working alone in rural areas. The following hypothesis reflects on the fairness components and conflicts in PAs. Hypothesis 3.

In health services mainly organized according to the "jungle" perspective,

1) the employees from nursing homes experience more fairness in performance appraisals than employees from home care

2) the employees from nursing homes experience less conflict in performance appraisals than employees from home care.

\subsection{Performance Appraisals Are Illustrated through a "Carnival" Perspective}

Bolman and Deal's fourth perspective is the carnival concept (Table 1), where PAs might be illuminated as a creative tool. The focus is on organizational culture and inspiration [10], along with attention to new procedures, and conversations among seniors [15]. However, a 360 degree [16] evaluation or PAs in small groups may also be other possible [19]-[21]. Knowledge about PAs may consist of a several elements, such as the clarity of their role in PAs, as well as understanding and accepting different procedures [22] [23]. Benner's learning perspective-from novice to expert could also be a part of this perspective [24].

With PAs in groups, the group pushes each member to perform his or her highest level, and thus conscientious members may be heavily motivated to participate in a PAs [25]. Participating parties can encourage the team to increase professional learning and development [19] [26]. However, employees involved in an individual PA may have more passive roles and may therefore feel that they have an inferior role in the PA. Research has shown that the PA must have a positive purpose, and employees must be participants in the PA if they are to improve their job performance [19]. Research also shows that employees acquire additional professional knowledge by having the PA in a group rather than in individual conversations [23].

Whereas other perspectives have focuses on organizational stability in PA, the carnival model is focused on flexibility [15]. Flexibility may also be linked to multidisciplinary and interdisciplinary work, but also to jobs where the unexpected can happen [27]. Active participation may also be very important in this model as it increases the feeling of fairness in PAs [2]. Based upon previous research, I thus propose the following hypothesis:

Hypothesis 4.

In health services, mainly organized according to the "carnival" perspective, employees who have performance appraisal in groups may experience active and creative participation in the conversations to greater degrees than those who have individual performance appraisals.

\section{Methods}

\subsection{Sample}

1) Sample (Hypotheses 1-3, Table 2)

An 86-item questionnaire which was composed from previous research questionnaires concerning PA [28]-[31], was distributed to a representative sample of 600 health personnel from 25 municipalities in Norway. About 371 questionnaires were returned (response rate 62\%). The municipal office in each area sent a list of 25 randomly selected names and addresses of health professionals. The goal was to have an equal number of informants from all parts of the country. The respondents worked in nursing homes and home care, and were registered nurses (47\%) and auxiliary nurses (45\%), while the remaining $8 \%$ represented other professions, such as physiotherapists and social workers.

2) Sample (Hypotheses 4, Table 2)

Field work was done with test-groups and control-groups, where participants were recruited from various departments in one municipality. The test-groups had PAs in groups of three employees plus the manager. Both group types responded to the same questionnaires, which considered of previous researchers questionnaires [28]-[30] [32] [33]. The questionnaires were collected at three different points in time. A pre-test was given a week before the first PA, and post-test 1 was collected two weeks after the first PA. Post-test 2 was collected three weeks after the second PA, which was conducted one year after the first PA. The questionnaires were distributed to a representative sample of respondents. That is, 30 employees who had individual Pas and 30 employees who had group-PAs. The pre-test was completed by 29 group-PA respondents and 27 individual PA respondents. Post-test 1 was answered by 28 group-PA respondents and 25 individual PA respondents, and posttest 2 was completed by 22 group-PA respondents and 17 individual PA respondents. Most respondents were 
Table 2. Hypotheses with values from SPSS measurements.

\begin{tabular}{|c|c|c|c|c|c|}
\hline Hypotheses & $\begin{array}{l}\text { Cronbach's } \\
\text { alpha }\end{array}$ & KMO & $\begin{array}{l}\text { Analysis } \\
\mathrm{N}\end{array}$ & t-value & $\begin{array}{c}\text { Standard } \\
\text { coefficient }\end{array}$ \\
\hline $\begin{array}{c}\text { 1: Factory perspectives- } \\
\text { PA training }\end{array}$ & Dummy & & & $\begin{array}{l}\mathrm{S}:-0.29 \\
\mathrm{M}: 1.70^{*}\end{array}$ & $\begin{array}{c}-0.02 \\
0.32\end{array}$ \\
\hline $\begin{array}{l}\text { 2: Family perspective- } \\
\text { exchanges and dyadic } \\
\text { relationships in PA }\end{array}$ & 0.91 & 0.921 & 330 & $\begin{array}{l}\mathrm{N}: 2.24^{* * *} \\
\mathrm{~A}: 1.51\end{array}$ & $\begin{array}{l}0.170 \\
0.104\end{array}$ \\
\hline $\begin{array}{l}\text { 3: Jungle perspective-_- } \\
\text { conflicts and fairness in PAs }\end{array}$ & 0.87 & 0.809 & 320 & $\begin{array}{c}\text { NH: } 2.09^{* *} \\
\text { HC: } 0.04\end{array}$ & $\begin{array}{l}0.152 \\
0.003\end{array}$ \\
\hline $\begin{array}{l}\text { 4: Carnival perspective- } \\
\text { culture and participation (group } \\
\text { PA) in PAs }\end{array}$ & 0.71 & 0.00 & 25 & $\begin{array}{l}\mathrm{G}: 2.37^{* *} \\
\mathrm{I}: 0.93\end{array}$ & $\begin{array}{l}0.03 \\
0.37\end{array}$ \\
\hline
\end{tabular}

$\overline{{ }^{* * *}} p<0.01{ }^{* *} p<0.05{ }^{*} p<0.10$. S: subordinate M: manager $\mathrm{N}$ : nurse A: auxiliary nurse NH. nursing home HC: home care G: group PA I: individual PA.

educated nurses (24\%) and auxiliary nurses (52\%), whereas the remaining $24 \%$ of respondents represented cleaners, janitors and nonqualified staff.

\subsection{Data Analysis}

Data from this quantitative study were processed by using SPSS 16-18. Factor analysis and regression analysis were used (multivariate analysis), as demonstrated in Table 2.

\subsection{Measurements}

Hypothesis 1 consists of a dummy analysis measuring “yes” or "no" responses. Dummy-variables were used when analysing PA training. All scales in the questionnaire were quality assured according to their Cronbach's alpha values, aside from the questions for the dummy variable. All other questions were measured by using a five-point Likert scale, ranging from $1=$ strongly disagree to $5=$ strongly agree.

\subsection{Ethical Considerations}

The cover letter informed the participants about the study's purpose, what participation involved and that it was voluntary and anonymous. The Norwegian Social Science Data Service (NSD) in Bergen approved the study.

\section{Results}

H1: When training in PAs is measured organizations primarily arranged according to the factory perspective have managers at a t-value of 1.70 and subordinates at a t-value of -0.29 . Managers have the highest values, and they are the only ones who receive enough training in PA techniques (Table 2).

$\mathrm{H} 2$ : When dyadic relationships in PAs are measured organizations primarily composed by the family perspective have nurses at a t-value of 2.24 and auxiliary nurses at a t-value of 1.51. Nurses have the highest t-value and are thus the professional group who experiences the highest number of dyadic relationships and exchanges in PAs (Table 2).

H3: When justice in PA is measured organizations primarily composed by the jungle perspective have the nursing-home employees at a t-value of 2.09 and home-care employees at a t-value of 0.04. Employees from nursing homes have the highest t-value, and thus they work at institutions that have the most justice in PAs (Table 2).

H4: In organizations primarily arranged according to the carnival perspective, informants in the group-PAs are more active participants (t-value of 2.37) in the conversations than employees who have individual conversations in PAs (t-value of 0.93). That is, the group-PA is generally more participatory in the conversation process than those who have individual conversations (Table 2).

\section{Discussion}

PAs can be implemented differently across various health organizations, departments, and regions, and from one 
decade to the next [1]-[5] [7] [9]. Health organizations primarily composed according to the factory perspective more often have rigid rules for procedures and implementations, and strict procedures for tools such as PAs. At the same time, organizations under the factory arrangement generally have a strict management hierarchy, and thus more often focus on management's education. PAs will probably be affected by these arrangements [7].

This study cannot ignore that being responsibility for approximately 70 - 80 PAs may be result in conversation number that exceed the capacity of one manager. Moreover, the PA's purpose might weaken professional development and undermine benefits for both the employee and the organization. Therefore, it is easy to assume that managers are the only ones who need training in PA procedures. The employees are generally not thought of as needing PA training. It is unclear whether this training bias is derived from thoughtlessness or planned by top management.

While some organizations might operate under the assumption that subordinates should not know about management strategies, including PAs, research, however, reveals that all employees should be trained in PAs if high-quality conversations are sought after.

This allows employees to assume responsibility for their own PA conversations, knowing what to require of such a conversation and thus opening up for a high-quality PA outcome [4] [12]-[15]. Yethypothesis 1 is confirmed: health services mainly organized by "factory" perspective only trains managers in PA (Table 2).

In connection with Bolman and Deal's (2009) family model, high-quality exchange and communication at the workplace will lead to high-quality relationships in PAs [9]. A lack of dyadic exchanges and relationships is probably a contributing reason for why several auxiliary nurses viewed PAs as a useless tool in general. Previous research also indicates that employees with undergraduate degrees often have low degrees of job motivation and less inclined to participate and exchange in PAs [2], most likely because the work environment does not have or rarely has a good development strategy for all employees. There is reason to believe that all employees experience decreased job motivation when PAs are poorly prepared.

Furthermore, nurses often have the same educational level as their managers and are most likely given less criticism. Nurses, when compared to auxiliary nurses, may be better at pointing out errors in the system and discussing interesting topics, and have a greater opportunity to further their education [3] [8].

The Norwegian municipalities have limited resources, and competition between important tasks prevails. Consequently, PAs may be given lower priority or afforded little emphasis [6]. Moreover, managers in nursing homes have their offices at the department. The managers are thus a visible leader who sees the employees in their daily work in the department. This will probably lead to an openwork environment, where they solve problems immediately. By contrast, managers in home care very often have the office at the town hall. These managers rarely or never observe their subordinate during their daily work. Work problems, if they are ever addressed, will more often remain for a while. These challenges might also apply to the use of PAs.

There is reason to believe that municipalities vary and use different PA perspectives, based upon management strategies, work problems, financial or work-related changes. A municipality can use several of these perspectives in the same PA instance, consciously or unconsciously. This is primarily because municipalities have both home care and nursing homes, and they have employees with bachelor's degrees, high school diplomas, and ones lacking a formal education beyond health. Municipalities will also have many different managers with divergent personalities and work experiences. This can in turn affect the PAs and their outcomes.

Nurses in this study are the professional group who experiences the highest number of dyadic relationships and exchanges in PAs. Auxiliary nurses have less dyadic exchanges in PAs. That may indicate that nurses have experience more "family" perspective in PAs than auxiliary nurses. Hypothesis 2 about the "family" perspectives can be confirmed (Table 2).

Employees in nursing homes experience more justice in PAs, possibly because the nursing-home employee has a manager in the department, where and misunderstandings can be resolved immediately. The managers in nursing homes often have their offices at the actual facilities, and therefore will be more accessible with the employees. The home care employee, on the other hand, has a more peripheral relationship with their manager. Home care employees work alone in the countryside, and their managers often have an office in a government or public building. These managers are probably not available at any given time [17] [18]. Employees from nursing homes experience more fairness in PAs than employees who work at institutions. This shows that hypothesis 3 in confirmed in the context of the jungle, employees in nursing homes, versus those in home care (Table 2).

Whereas previous perspectives focused on stability, the "carnival" perspective stressed change and flexibility [10] [15]. The study shows that employees are more active participants in group-PA than by individual conver- 
sations [2]. This is because the group with colleagues discussing common issues and problems. The main focus of the PA-group is that members are flexible, reflective and listening as much as they are active and participatory [15] [23].

It may be wise to consider new PA models or to vary the models to suit various staffs. Being an active PA participant is especially important in PA-group because it is the group itself that is under evaluation [2] [23]. Maximizing participation can be achieved and conflicts are avoided when groups are arranged thoughtfully, where focus is placed on member compatibility. There will often be one or more members that can easily be manager and a dominant part. Moreover, individual PAs are often conducted in executive offices-i.e. the manager's territory. Group-PAs, by contrast, are often held in larger common rooms that are not necessarily the manager's territory. This can also be a contributing factor to the often greater activity levels in group-PAs. Therefore, hypothesis 4 is confirmed: in health services mainly organized by the "carnival" perspective, employees in group-PAs in may experience active and creative participation in the conversations to greater degrees than those who have individual PAs (Table 2).

There is reason to believe that health organizations do not represent pure factory, family, jungle or carnival types. Each organization might have a strong element of one of these perspectives, but other perspectives may also be visible. It also appears that the organizational approach in part is on the manager's personality, which therefore means that various departments in the same municipality might be organized differently.

\subsection{Validity and Reliability}

The study's high response rate suggests a robust validity and reliability. Moreover, the research method, with two data sets, also shows a breadth of employee experiences, thus strengthening the study. The fieldwork can be both strength and a weakness in the study: Everyone in the organization was surveyed, but the overall sample was not large enough to draw generalizations. All hypotheses are confirmed, as Cronbach alpha is over 07.

\subsection{Limitation}

The study was conducted in home care and in institutions, and focused only on nursing staff. While there is no reason to believe that the investigation would have been different in larger hospitals, additional research in these larger institutions is warranted.

\section{Conclusion and Generalization}

This study shows that health personnel involved in PAs experience different PA outcomes and employees working as a team member in the municipal health services need to experience high-quality relationship, justice and robust performance. Bolman and Deal's (2009) organizational perspectives may illuminate health services that are large, complicated and very different from municipality to municipality. It appears that the group-PA is not (yet) the most commonly used PA form in this sector, although group-PA, versus individual PAs, will more likely be used by an organization as a learning area. There is little previous research in the field from Norway (health service), and most is from various other countries. Still, this finding may be generalized to other research set- tings [2] [25] [29] [30].

\section{Conflict of Interests}

The author declares that she has no conflicts of interests.

\section{References}

[1] Boswell, W.R. and Bourdreau, J.W. (2002) Separating the Developmental and Evaluative Performance Appraisal. Journal of Business and Psychology, 16, 391-412. http://dx.doi.org/10.1023/A:1012872907525

[2] Murphy, K.R. and Cleveland, J.N. (1995) Understanding Performance Appraisal. Social, Organizational and Goal Setting, Sage Publications, Thousand Oaks.

[3] Holbrook, R.L. (2002) Contact Point and Flash Points: Conceptualizing the Use of Justice Mechanisms in the Performance Appraisal Interview. Human Resource Management Review, 12, 101-123. http://dx.doi.org/10.1016/S1053-4822(01)00053-5

[4] Fletcher, C. (2002) Performance Appraisal and Management: The Developing Research Agenda. Journal of Occupa- 
tional of Individual, 74, 473-487.

[5] Pettijohn, C., Pettijohn, L.S. and d’Àmico, M. (2001) Characteristics of Performance Appraisal and Their Impact on Sales force Satisfaction. Human Resource Development Quarterly, 12, 127-146. http://dx.doi.org/10.1002/hrdq.4

[6] White Paper No. 25 (2005-2006) Competence, Opportunities and Meaning. Government Stoltenberg.

[7] Vasset, F., Marnburg, E. and Furunes, T. (2010) Employees’ Perceptions of Justice in Performance Appraisal. Nursing Management, 17, 30-34. http://dx.doi.org/10.7748/nm2010.05.17.2.30.c7727

[8] Abrahamsen, B. (2002) Hvorfor utdanne to pleiere for å få en? In Institutt for samfunnsforskning (Institutt of social science), Pax Forlag, Oslo.

[9] Vasset, F., Marnburg, E. and Furunes, T. (2012) Dyadic Relationships and Exchanges in Performance Appraisal. Vård i Norden, 32, 4-9.

[10] Bolman, L.G. and Deal, T.E. (2009) Reframing Organizations, Artistry, Choice, and Leadership. Jossey-Bass, Inc, USA.

[11] Fletcher, C. (2008) Appraisal, Feedback and Development. Making Performance Review Work. 4th Edition, R.T.F. Group, New York.

[12] Bretz, R.D., Milkovich, G.T. and Read, W. (1992) The Current State of Performance Appraisal Research and Practice: Concerns, Directions, and Implications. Journal of Management, 18, 321-352. http://dx.doi.org/10.1177/014920639201800206

[13] Flint, D.H. (1999) The Role of Organizational Justice in Multi-Source Performance Appraisal: Theory-Based Applications and Directions for Research. Human Research Management Review, 9, 1-20. http://dx.doi.org/10.1016/S1053-4822(99)00009-1

[14] Glover, R.B. (2004) Why Are We Ignoring Performance Appraisal Research. Powered by BNET:COM, 1-4.

[15] Mikkelsen, A. (2005) Medarbeidersamtalen i det nye arbeidslivet. Cappelen Akademiske Forlag, Oslo.

[16] Tourish, D. (2006) The Appraisal Interview Reappraised. In: The Handbook of Communication Skills, Routledge, London.

[17] Blix, E.S. (1999) Et kappløp med tiden? In: Publikasjonsserie 9, Universitetet i Oslo, Oslo.

[18] O’Connor, M. and Lee, S. (2007) Authentic Performance Appraisal: When Home Is the Workplace. International Journal of Palliative Nursing, 13, 606-609.

[19] Wang, W. (2006) Evaluation of $2+2$ Alternative Teacher Performance Appraisal Program in Shanxi, People’s Republic of China. Teaching and Teacher Education, 23, 1012-1023.

[20] Edwards, M. and Sproull, R. (1985) Making Performance Appraisal Perform: The Use of Team Evaluation. American Management Association's HR Focus New York. The Association, 62, 28-32.

[21] Lanza, P. (1985) Team Appraisal. Personnel Journal, 47-51.

[22] Kavanagh, P., Benson, J. and Brown, M. (2007) Understanding Performance Appraisal Fairness. Asia Pacific Journal of Human Resources, 45, 132-150. http://dx.doi.org/10.1177/1038411107079108

[23] Vasset, F., Marnburg, E. and Furunes, T. (2012) Exploring Different Effects of Performance Appraisal in Group and Individual Conversations. Vård i Norden, 32, 36-41.

[24] Benner, P. (1984) From Novice to Expert. University of California, San Francisco.

[25] English, A., Griffith, R.L. and Steelamn, L. (2007) Small Group Research. 633-665. http://sgr.sagepub.com

[26] West, M.A. and Hirst, G. (2003) Cooperation and Teamwork for Innovation. In: West, M.A., Tjosvold, D. and Smith, K.G., Ed., International Handbook of Organizational Teamwork and Cooperative Working, John Wiley and Sons, Hoboken.

[27] Orvik, A. (2004) Organisatorisk Kompetanse. Cappelens Forlag, Oslo.

[28] Graen, G.B. and Uhl-Bien, M. (1995) Relationship-Based Approach to Leadership: Development and Leader-Member Exchange (LMX) Theory of Leadership over 25 Years: Applying a Multi-Level Multi-Domain Perspective. Leadership Quarterly, 6, 219-247. http://dx.doi.org/10.1016/1048-9843(95)90036-5

[29] Yeuk-Mui May, T., Korczynski, M. and Frenkel, S.J. (2002) Organizational and Occupational Commitment: Knowledge Workers in Large Corporations. Journal of Management Studies, 39, 775-801. http://dx.doi.org/10.1111/1467-6486.00311

[30] Kuvaas, B. (2006) Performance Appraisal Satisfaction and Employee Outcomes: Mediating and Moderating Roles of Work Motivation. International Journal of Human Resource Management, 17, 504-522.

[31] Korsgaard, M.A. and Robertson, L. (1995) Procedural Justice in Performance Evaluation: The Role of Instrumental and Non-Instrumental Voice in Performance Appraisal Discussions. Journal of Management, 21, 657-669.

http://dx.doi.org/10.1177/014920639502100404 
[32] Spence, D.G. and Wood, E.E. (2007) Registered Nurse Participation in Performance Appraisal Interview. Journal of Professional Nursing, 23, 55-59. http://dx.doi.org/10.1016/j.profnurs.2005.11.003

[33] Kuvaas, B. (2007) Different Relationships between Perceptions of Developmental Performance Appraisal and Work Performance. Personnel Review, 36, 378-397. 